\title{
Activation of dihydrogen on supported and unsupported silver catalysts
}

\author{
J. Hohmeyer ${ }^{1,2}$, E.V. Kondratenko ${ }^{3}$, M. Bron ${ }^{2,4}$, J. Kröhnert ${ }^{1}$, F.C. Jentoft ${ }^{1,5}$, R. Schlögl $1^{1}$, P. Claus ${ }^{2^{*}}$ \\ ${ }^{1}$ Department of Inorganic Chemistry, Fritz-Haber-Institute of the Max-Planck-Society, Faradayweg 4-6, D-14195 \\ Berlin, Germany \\ ${ }^{2}$ Dept. Chemistry, Ernst-Berl-Institute, Chemical Technology II, Technische Universität Darmstadt, Petersenstr. 20, \\ D-64287 Darmstadt, Germany \\ ${ }^{3}$ Leibniz-Institute for Catalysis e.V. at the University of Rostock, Albert-Einstein-Str. 29a, D-18059 Rostock, Ger- \\ many \\ ${ }^{4}$ present address: Ruhr-Universität Bochum, Analytische Chemie - Elektroanalytik und Sensorik, Nachwuchsgruppe \\ Brennstoffzellen,Universitätsstrasse 150, D-44780 Bochum, Germany \\ ${ }^{5}$ new address: School of Chemical, Biological and Materials Engineering, University of Oklahoma, 100 East Boyd \\ Street, Norman, OK 73019-1004, USA
}

"Corresponding author: e-mail claus@ct.chemie.tu-darmstadt.de,

Received 17 July 2009, Revised 2 October 2009, Accepted 7 October 2009 Available online 14 November 2009

\begin{abstract}
The activation of dihydrogen on silica, silver, and silica-supported silver ( $9 \mathrm{wt} \% \mathrm{Ag}$ ) was investigated. Both, silica and silver are individually able to dissociate dihydrogen. Silanol groups on silica undergo $\mathrm{H} \rightarrow \mathrm{D}$ exchange at $393 \mathrm{~K}$ in $\mathrm{D}_{2}$ as detected by IR spectroscopy. HD is observed in temporal analysis of products (TAP) experiments when $\mathrm{H}_{2}$ and $\mathrm{D}_{2}$ are sequentially pulsed on silver at $673 \mathrm{~K}$; even when the time delay between the isotopes is $4 \mathrm{~s}$, HD is formed, indicating that long-lived surface hydrogen species are present. Differential scanning calorimetry (DSC) shows that the activation of dihydrogen is an activated process: heat signals evoked through $\mathrm{H}_{2}$ pulses on $\mathrm{Ag} / \mathrm{SiO}_{2}$ grow with increasing temperature (373-523 K). Nonetheless, the presence of silver on the silica surface accelerates the $\mathrm{Si}-\mathrm{OH} \rightarrow \mathrm{Si}-\mathrm{OD}$ exchange. Investigation of the exchange kinetics on $\mathrm{Ag} / \mathrm{SiO}_{2}$ shows that diffusion processes of activated hydrogen species are rate-determining at higher temperatures $(\geq 373 \mathrm{~K})$, when activation of $\mathrm{D}_{2}$ on silver becomes facile. Indications of diffusion limitation are observed already at $313 \mathrm{~K}$ on Pt/SiO 2 . TAP and DSC measurements show that $\mathrm{H}_{2}$ is more readily activated on silver that has been treated in $\mathrm{O}_{2}$ at $673 \mathrm{~K}$ followed by reduction in $\mathrm{H}_{2}$ at $673 \mathrm{~K}$. Morphological changes induced to the silver surfaces or (sub)surface oxygen species are presumed responsible for this effect
\end{abstract}

Keywords: silver catalysts, silica, hydrogen, dissociative adsorption, isotopic exchange, temporal analysis of products (TAP), differential scanning calorimetry (DSC), infrared spectroscopy (FTIR)

\section{Introduction}

Silver is an active component in oxidation catalysts [1-13]; most well known is its industrial application for ethene epoxidation. However, silver can also be used as a catalyst for reduction reactions, for example selective hydrogenation of unsaturated aldehydes such as acrolein and crotonaldehyde [14-16] or citral [17,18]. Silver catalysts favor the formation of the industrially relevant unsaturated alcohols, whereas mainly saturated aldehydes are formed on conventional hydrogenation catalysts such as $\mathrm{Pt} / \mathrm{SiO}_{2}$. Comparison of the different behavior of these two metals in these simple parallel reactions could give hints as to the source of selectivity and lead to an approach for the rational design of such catalysts. To evaluate the selectivity, the interaction of the catalysts with both reactants has to be considered. Here, we focus on understanding the activation of hydrogen on silver-containing materials. Because of the 
complexity of the catalyst, its individual components, that is, silver and the silica support, will first be considered separately and then in combination.

Literature reports on the interaction of $\mathrm{H}_{2}$ with unsupported silver give a consistent picture. No measurable quantities of molecular $\mathrm{H}_{2}$ adsorb on silver [19-21]; and only at very low temperature, can $\mathrm{H}_{2}$ be condensed onto the surface [22,23]. Dissociation of hydrogen molecules on clean silver surfaces is predicted by theoretical calculations [24-26] to be an endothermic process. Zhukov et al. [27] report that at ambient temperatures $\mathrm{H}_{2}$ molecules do not adsorb dissociatively on single crystal silver surfaces. The solubility of $\mathrm{H}_{2}$ in silver is low [28] over a wide temperature and pressure range [29]; Kluthe et al. [30] report $10^{-14}$ $\mathrm{H} / \mathrm{Ag}$ at $296 \mathrm{~K}$. Evidence is available for the activation of $\mathrm{H}_{2}$ on silver at elevated temperature; for example, the presence of $\mathrm{H}_{2}$ promotes the homoexchange of ethylene on supported silver at $480 \mathrm{~K}$ [31]. The exchange between $\mathrm{H}_{2}$ and $\mathrm{D}_{2}$ proceeds at 603-673 K [32] and oxygen impurities seem to have a positive effect on this reaction. The general lack of affinity of silver toward $\mathrm{H}_{2}$, in comparison to other metals such as nickel, palladium, or platinum is ascribed to the filled d-band of silver [32,33].

The ability of oxide supports to interact with hydrogen is evidenced by the formation of HD from mixtures of $\mathrm{H}_{2}$ and $\mathrm{D}_{2}$. Silica [34], alumina [35-38], and mixed silicaalumina materials [39] all catalyze this exchange; provided they have been activated through a thermal pretreatment. Silica has been used as a catalyst in the hydrogenation of alkenes [40]. Another indicator of the activation of hydrogen on oxide surfaces is the exchange of $\mathrm{OH}$ to $\mathrm{OD}$ groups in presence of $\mathrm{D}_{2}$, which can be monitored by IR spectroscopy $[14,41,42]$. This exchange occurs on both alumina [42-44] and silica [41,45] at elevated temperatures; again, thermal activation of the materials seems to be important. Carter et al. [42] found a logarithmic rate law for the exchange on alumina. The formation of surface OD groups indicates that hydrogen is activated at or near surface $\mathrm{OH}$ groups, or can migrate. Addition of a metal opens up another mechanistic pathway for the exchange; in the presence of platinum the rate of $\mathrm{D}_{2}$-induced exchange of $\mathrm{OH}$ groups to OD groups on alumina was increased [42].

Interaction of hydrogen with silver and support in $\mathrm{Ag} / \mathrm{SiO}_{2}, \mathrm{Ag} / \mathrm{Al}_{2} \mathrm{O}_{3}$ and $\mathrm{Ag} / \mathrm{TiO}_{2}$ catalysts has been described in the literature. Reported data include $\mathrm{H}_{2}$ chemisorption on $\mathrm{Ag} / \mathrm{TiO}_{2}$ [46], kinetics of $\mathrm{H}_{2} / \mathrm{D}_{2}$ exchange on $\mathrm{Ag} / \mathrm{Al}_{2} \mathrm{O}_{3}$ [47], $\mathrm{H}_{2}$-promoted ethene isotopic homoexchange on $\mathrm{Ag} / \mathrm{SiO}_{2}$ [31], hydrogenation of ethene on $\mathrm{Ag} / \mathrm{SiO}_{2}$, and selective hydrogenation of $\alpha, \beta$-unsaturated aldehydes [15-17,48,49].

The affinity of silver toward oxygen is well known [50,51], and a variety of oxygen species dissolved in the bulk, in the subsurface region, and on the surface of silver have been described [51-52]. Exposure of silver to $\mathrm{O}_{2}$ at temperatures between 800-1023 $\mathrm{K}$ induces massive changes in the surface morphology [51,52]; and the use of silver in oxidation reactions (of methane or methanol) can lead to similar effects $[9,11]$. A pretreatment of silver catalysts in $\mathrm{O}_{2}$ affects the adsorption [53] and conversion of $\mathrm{CO}$ [54,55]. A few publications indicate that a pre-treatment in $\mathrm{O}_{2}$ affects the interaction of silver with hydrogen. Theoretical calculations predict that silver atoms in the proximity of oxygen exhibit a higher affinity toward $\mathrm{H}_{2}$ [56,57]. Experiments show that the hydrogen adsorption capacity increases after a heat treatment in $\mathrm{O}_{2}$ [21,58]. Moreover, oxygen impurities on the surface, which are difficult to remove [59], are believed to be responsible for the lower activation energy in the $\mathrm{H}_{2}-\mathrm{D}_{2}$-exchange reaction that is observed for granular silver in comparison to silver foil [32]. Recent investigations show that an $\mathrm{O}_{2}$ pretreatment enhances the performance of supported silver catalysts in the hydrogenation of $\alpha, \beta$-unsaturated aldehydes [60].

The goal of this work is to clarify whether the dissociative adsorption of $\mathrm{H}_{2}$ on silver is endo- or exothermic and to evaluate whether a significant coverage of activated hydrogen is to be expected on the silver and perhaps also on the support under typical hydrogenation conditions. The activity of silver, silica, and silica-supported silver in the activation of $\mathrm{H}_{2}$ is compared, and the effect of an $\mathrm{O}_{2}$ pretreatment is investigated. The temporal analysis of products (TAP) reactor, differential scanning calorimetry (DSC) and FTIR spectroscopy are used to monitor $\mathrm{H}_{2}-\mathrm{D}_{2}$ exchange, $\mathrm{H}_{2}$ adsorption, and exchange of surface $\mathrm{OH}$ of the support to OD groups with $D_{2}$. The $\mathrm{H}_{2}-\mathrm{D}_{2}$ exchange and the isotopic exchange reaction of $\mathrm{Si}-\mathrm{OH}$ to $\mathrm{Si}-\mathrm{OD}$ groups require the activation and cleavage of dihydrogen molecules. The factors influencing this key step are identified and the implications for selective hydrogenations are discussed.

\section{Experimental section}

\subsection{Catalyst preparation}

\subsection{1. $9 \mathrm{Ag} / \mathrm{SiO}_{2}$-iw and $5 \mathrm{Ag} / \mathrm{SiO}_{2}$-iw}

Catalysts containing $9 \mathrm{wt} \%$ silver supported on silica were prepared by the incipient wetness technique. Silica (Alfa - Johnson Matthey; "silica gel, large pore"; $\mathrm{S}_{\mathrm{BET}}=$ $253 \mathrm{~m}^{2} \cdot \mathrm{g}^{-1} ; 0.2 \mathrm{~mm}<\mathrm{d}_{\text {particle }}<0.5 \mathrm{~mm}$ ) was dried in vacuum at $373 \mathrm{~K}$ for $16 \mathrm{~h}$. An aqueous solution of silver lactate was slowly added and the resulting material was dried in an extractor hood for $48 \mathrm{~h}$ at room temperature and for another $2 \mathrm{~h}$ at $333 \mathrm{~K}$ under vacuum. Reduction was carried out in a $\mathrm{H}_{2}$ flow $\left(145 \mathrm{~cm}^{3} \cdot \mathrm{min}^{-1}\right)$ at $598 \mathrm{~K}$ for $2 \mathrm{~h}$ applying heating and cooling rates of $5 \mathrm{~K} \cdot \mathrm{min}^{-1}$.

\subsection{2. $10 \mathrm{Ag} / \mathrm{SiO}_{2}-\mathrm{imp}$}

A catalyst containing $10 \mathrm{wt} \%$ silver was prepared by impregnation of silica (Aerosil 200, Degussa) with an aqueous solution of $\mathrm{AgNO}_{3}$ (Fluka). Impregnation was 

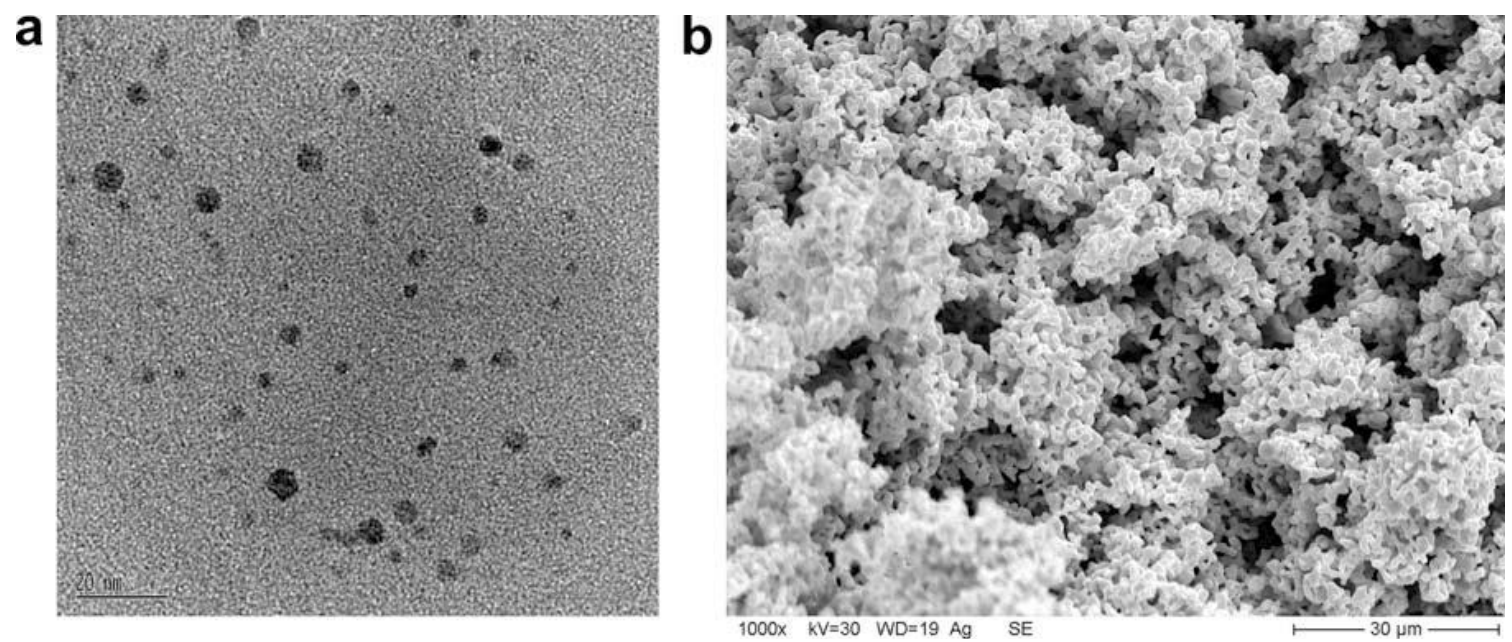

Fig. 1: (a) TEM image of $9 \mathrm{Ag} / \mathrm{SiO}_{2}$-iw. (b) $\mathrm{SEM}$ image of silver obtained through the reduction of $\mathrm{Ag}_{2} \mathrm{O}$ at $673 \mathrm{~K}$.

followed by drying ( $373 \mathrm{~K}, 12 \mathrm{~h}$ ), calcination in flowing air ( $448 \mathrm{~K}$ ), and reduction in flowing $\mathrm{H}_{2}$ at $523 \mathrm{~K}$ for $3 \mathrm{~h}$.

\subsection{3. $\mathrm{SiO}_{2}$ (lactic acid)}

A reference sample, $\mathrm{SiO}_{2}$ (1.a.), was prepared in an identical manner to $9 \mathrm{Ag} / \mathrm{SiO}_{2}$-iw, only the silver lactate solution was replaced by a solution of lactic acid in water.

\subsubsection{Silver}

Unsupported silver was obtained by an in situreduction of silver(I) oxide (Johnson Matthey) in the TAP reactor. After evacuation the $\mathrm{Ag}_{2} \mathrm{O}$ was reduced in a $\mathrm{H}_{2}$ flow $\left(30 \mathrm{~cm}^{3} \mathrm{~min}^{-1}\right)$ at $673 \mathrm{~K}$ for $20 \mathrm{~min}$; a heating rate of $10 \mathrm{~K} \cdot \mathrm{min}^{-1}$ was applied. Finally the reactor was evacuated again at $673 \mathrm{~K}$ before the start of the experiment. Fig. 1 shows a scanning electron microscopy image (ZEISS DSM 962 , operated at $30 \mathrm{keV}$ ) of an analogously prepared sample. The preparation yields silver in a sponge-like morphology (cf. [61]) with particle diameters of a few $\mu \mathrm{m}$, which probably can be rather compared to the granular silver in the work of Mikovsky et al. [32] than the silver foil.

\subsection{5. $6 \mathrm{Pt} / \mathrm{SiO}_{2}-\mathrm{iw}$}

A catalyst containing $6 \mathrm{wt} \%$ platinum on silica was prepared by the incipient wetness technique. Silica (Alfa Johnson Matthey; "silica gel, large pore"; $\mathrm{S}_{\mathrm{BET}}=253 \mathrm{~m}^{2} \cdot \mathrm{g}^{\text {- }}$ ${ }^{1} ; 0.2 \mathrm{~mm}<\mathrm{d}_{\text {particle }}<0.5 \mathrm{~mm}$ ) was dried in vacuum at 393 $\mathrm{K}$ for $3 \mathrm{~h}$. An aqueous solution of tetramine-platinum(II) nitrate (Alfa Aesar) was slowly added and the resulting material was dried in a desiccator for $48 \mathrm{~h}$ and for another 2 $\mathrm{h}$ at $363 \mathrm{~K}$ in $\mathrm{N}_{2}$ flow. The resulting material was calcined in air flow at $523 \mathrm{~K}$ for $4 \mathrm{~h}\left(1 \mathrm{~K} \cdot \mathrm{min}^{-1}\right)$. Reduction was carried out in $\mathrm{H}_{2}$ flow $\left(167 \mathrm{~cm}^{3} \cdot \mathrm{min}^{-1}\right)$ at $598 \mathrm{~K}$ for $4 \mathrm{~h}$ applying heating and cooling rates of $5 \mathrm{~K} \cdot \mathrm{min}^{-1}$.

\subsection{Analytical Methods}

\subsubsection{Temporal analysis of products (TAP)}

Heterogeneous H/D isotopic exchange on silver was investigated in a TAP-2 reactor, which is described in detail elsewhere [62,63]. $68 \mathrm{mg}$ of $\mathrm{Ag}_{2} \mathrm{O}$ were placed within two layers of quartz particles $(250-30 \mu \mathrm{m})$ in the isothermal zone of the TAP-reactor and were reduced as described above. Two gas mixtures of $\mathrm{H}_{2} / \mathrm{Ne}=1 / 1$ and $\mathrm{D}_{2} / \mathrm{Xe}=1 / 1$ composition were then sequentially pulsed onto the silver at $673 \mathrm{~K}$. The time delay between the mixtures was varied from $0 \mathrm{~s}$ (simultaneous pulsing) to $4.0 \mathrm{~s}$ to gather information about the average lifetime of possible adsorbed $\mathrm{H}$ containing species. The pulse size of $\mathrm{Ne}$ and $\mathrm{Xe}$ was in the range of $10^{14}-10^{15}$ molecules (Knudsen diffusion regime). Transient responses were monitored at mass charge ratios $(\mathrm{m} / \mathrm{Q})$ related to reactants, reaction products, and inert gases at the reactor outlet using a quadruple mass spectrometer (Hiden Analytical HAL RC 301). The following mass charge ratios were recorded: $2\left(\mathrm{H}_{2}\right), 3(\mathrm{HD}), 4\left(\mathrm{D}_{2}\right), 20(\mathrm{Ne})$ and $132(\mathrm{Xe})$. The $\mathrm{H}_{2} / \mathrm{Ne}=1 / 1$ and $\mathrm{D}_{2} / \mathrm{Xe}=1 / 1$ pulses were repeated 10 times for each $\mathrm{m} / \mathrm{Q}$ and the corresponding signals were averaged to improve the signal to noise ratio. A blank measurement was performed on quartz particles.

After the described pulse experiments, the silver was treated by $\mathrm{O}_{2}$ pulses (ca. $144 \mathrm{nmol}$ of $\mathrm{O}_{2}$ in total) at $673 \mathrm{~K}$. After a subsequent reducing step in flowing $\mathrm{H}_{2}$ at $673 \mathrm{~K}$ for $0.2 \mathrm{~h}$, no water was observed when $\mathrm{H}_{2}$ was pulsed. The $\mathrm{H}_{2-}$ $\mathrm{D}_{2}$ sequential pulse experiments were then repeated. 

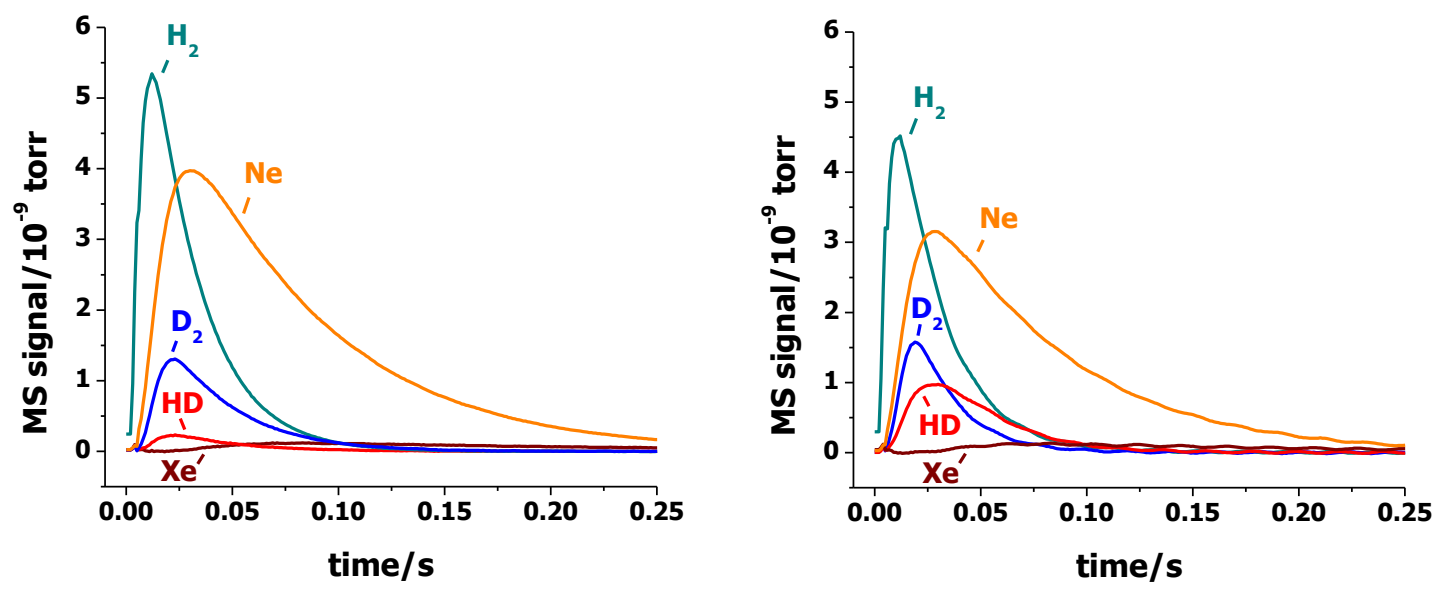

Fig. 2: Transient responses of $\mathrm{Ne}, \mathrm{Xe}, \mathrm{D}_{2}, \mathrm{HD}$, and $\mathrm{H}_{2}$ upon simultaneous pulsing of $\mathrm{H}_{2}\left(\mathrm{H}_{2} / \mathrm{Ne}=1\right)$ and $\mathrm{D}_{2}\left(\mathrm{D}_{2} / \mathrm{Xe}=1\right)$ at $673 \mathrm{~K}$ on (a) quartz and (b) support-free silver.
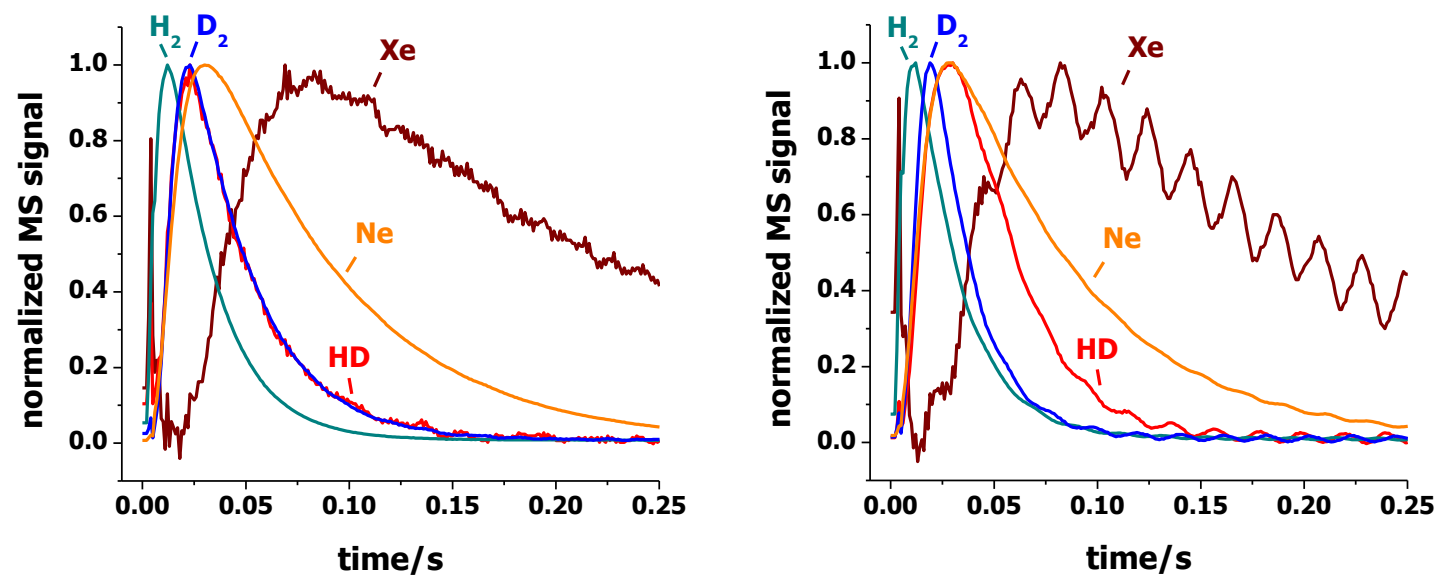

Fig. 3: Height-normalized transient responses of $\mathrm{Ne}, \mathrm{Xe}, \mathrm{D}_{2}, \mathrm{HD}$, and $\mathrm{H}_{2}$ upon simultaneous pulsing of $\mathrm{H}_{2}\left(\mathrm{H}_{2} / \mathrm{Ne}=1\right)$ and $\mathrm{D}_{2}\left(\mathrm{D}_{2} / \mathrm{Xe}=1\right)$ at $673 \mathrm{~K}$ on (a) quartz and (b) support-free silver.

\subsubsection{Differential scanning calorimetry (DSC)}

Hydrogen adsorption calorimetry was performed with a Setaram DSC111 differential scanning calorimeter. The carrier gas (argon 99.999\%) was further purified by a BTS cartridge to remove trace amounts of $\mathrm{O}_{2}$ and by a molecular sieve cartridge to remove water. The apparatus allows dosing small amounts of hydrogen, typically $10^{-7} \mathrm{~mol}$ $\mathrm{H}_{2}$, into the carrier gas. Approximately $80 \mathrm{mg}$ of catalyst was filled in a quartz reactor tube, which was placed in the calorimetric block and purged with the carrier gas.

Standard pre-treatment ("PT1") of the catalysts consisted of reduction in a flow of $\mathrm{H}_{2}\left(48 \mathrm{~cm}^{3} \cdot \mathrm{min}^{-1}\right)$ at $598 \mathrm{~K}$ for $2 \mathrm{~h}$ followed by a purge in flowing argon for $2 \mathrm{~h}$ at 598 K. Finally the catalyst was cooled to a selected temperature in the range $373-598 \mathrm{~K}$. Heating and cooling rates were 10 $\mathrm{K} \cdot \mathrm{min}^{-1}$ during the pre-treatment.
To determine the effect of treatment in $\mathrm{O}_{2}$, the standard reducing pre-treatment was modified and a third pretreatment including exposure to $\mathrm{O}_{2}$ was applied. During the modified reducing pre-treatment ("PT2") the catalysts were heated to $578 \mathrm{~K}$ at a rate of $10 \mathrm{~K} \cdot \mathrm{min}^{-1}$ in an argon flow and remained under these conditions for $100 \mathrm{~min}$. Hereafter the reduction was carried out in a flow of $\mathrm{H}_{2}$ for $150 \mathrm{~min}$ followed by a purge in argon for 130 min before starting the experiment. The corresponding pre-treatment including exposure to $\mathrm{O}_{2}$ ("PT3") was similar to PT2, but the initial period of $100 \mathrm{~min}$ in argon at $578 \mathrm{~K}$ was replaced by the following sequence: $15 \mathrm{~min}$ in argon, $75 \mathrm{~min}$ in $\mathrm{O}_{2}$, and 10 min in argon.

The DSC reactor effluent stream was analyzed by a Pfeiffer QMS 422 mass spectrometer. 


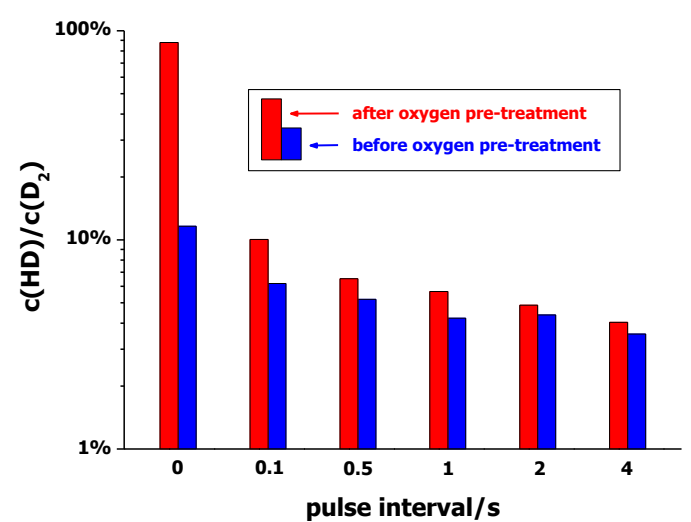

Fig. 4: The ratio of outlet concentrations of $H D$ and $D_{2}$ in the $D_{2}$ pulse upon sequential pulsing of $\mathrm{H}_{2} / \mathrm{Ne}=1 / 1$ and $\mathrm{D}_{2} / \mathrm{Xe}=1 / 1$ with different time delays $(\Delta \mathrm{t})$ on non-pretreated (blue bars) and $\mathrm{O}_{2-}$ pretreated (red bars) unsupported silver at $673 \mathrm{~K}$.

\subsubsection{IR spectroscopy}

Transmission infrared measurements were carried out with a Perkin Elmer S 2000 FTIR spectrometer with an integrated in situ quartz cell sealed by $\mathrm{CaF}_{2}$ windows. The powder samples were pressed to self-supporting wafers with an approximate area weight of $10 \mathrm{mg} \cdot \mathrm{cm}^{-2}$. Pretreatment was identical for all of the samples: evacuation at room temperature, followed by reduction in $\mathrm{H}_{2}(1 \mathrm{bar})$ at $598 \mathrm{~K}$ for $2 \mathrm{~h}$ (a heating rate of $10 \mathrm{~K} \cdot \mathrm{min}^{-1}$ was applied). Evacuation to $1 \cdot 10^{-6}$ mbar at $598 \mathrm{~K}$ for another $2 \mathrm{~h}$ was performed to remove formed water before cooling (10 $\mathrm{K} \cdot \mathrm{min}^{-1}$ ) to the desired temperature in the range 313-393 $\mathrm{K}$. A final pressure of $110 \mathrm{mbar}$ of $\mathrm{D}_{2}$ was introduced to the cell. During the exchange process spectra were continuously recorded and related to the background spectrum taken of the empty cell immediately before dosing deuterium into the cell. Each spectrum (16 scans) was recorded in the wavenumber range of 5500-900 $\mathrm{cm}^{-1}$. Spectra were converted from transmittance to absorbance, and the $\mathrm{OH}$ and $\mathrm{OD}$ band areas were determined through integration in the ranges 3800 to $3200 \mathrm{~cm}^{-1}$ and $2800-2450 \mathrm{~cm}^{-1}$, respectively (as indicated in Fig. 6b).

\section{Results}

\subsection{TAP}

To probe the activity of silver for activation of dihydrogen, $\mathrm{H}_{2} / \mathrm{Ne}=1 / 1$ and $\mathrm{D}_{2} / \mathrm{Xe}=1 / 1$ mixtures were sequentially pulsed at $673 \mathrm{~K}$ with time delays of $0-4 \mathrm{~s}$ between the pulses. The non-normalized transient responses of $\mathrm{Ne}$, $\mathrm{Xe}, \mathrm{H}_{2}, \mathrm{HD}$, and $\mathrm{D}_{2}$ recorded in the experiments with a time delay of $0 \mathrm{~s}$ are shown in Fig. $2 \mathrm{a}+\mathrm{b}$. Only minute amounts of HD are detected in the pulse that passed through a quartz bed, whereas metallic silver produces significant amounts of HD. The formation of HD on silver is corroborated by analysis of the shapes of the heightnormalized transients of $\mathrm{H}_{2}, \mathrm{HD}$, and $\mathrm{D}_{2}$ in Fig. $3 \mathrm{a}+\mathrm{b}$. According to the laws of diffusion, a $\mathrm{HD}$ impurity in $\mathrm{H}_{2}$ or $\mathrm{D}_{2}$ would evolve between $\mathrm{H}_{2}$ and $\mathrm{D}_{2}$. If $\mathrm{HD}$ is a reaction product, its transient should appear after that of $\mathrm{D}_{2}$. Fig. 3a illustrates that the transients of $\mathrm{HD}$ and $\mathrm{D}_{2}$ recorded in the experiment with the quartz particles are congruent and offset from the $\mathrm{H}_{2}$ curve. These data indicate that the HD signal is an artifact caused by the limited resolution of the MS. A small signal at $\mathrm{m} / \mathrm{Q}=3$ is recorded during analysis of $\mathrm{D}_{2}$, making impossible the detection of low amounts of $\mathrm{HD}$ in excess of $\mathrm{D}_{2}$. The formation of HD on silver is evidenced by the fact that the HD response is significantly delayed compared to the $\mathrm{D}_{2}$ response. This delay in response is even observed when applying a spacing of $4.0 \mathrm{~s}$ between the $\mathrm{H}_{2}$ and $\mathrm{D}_{2}$ pulses (not shown), whereby the offset between the HD- and $\mathrm{D}_{2}$-transients diminishes with increasing time delays. To quantify the effect of the time delay on the HD formation and thus on the lifetime of hydrogen species on the surface, the ratios of the HD and $\mathrm{D}_{2}$ concentrations were calculated for each time delay (Fig. 4). The highest ratio is observed when $\mathrm{H}_{2}$ and $\mathrm{D}_{2}$ are simultaneously pulsed. The ratio decreases with increasing time delay indicating that surface hydrogen species desorb as gasphase $\mathrm{H}_{2}$ or become non-reactive.

The H/D isotopic exchange experiments were repeated after the silver had been treated by $\mathrm{O}_{2}$ pulses at 673 $\mathrm{K}$ followed by reduction in $\mathrm{H}_{2}$ at the same temperature for $0.2 \mathrm{~h}$. No water was detected when $\mathrm{H}_{2}$ was pulsed over the material after the reducing treatment; hence no oxygen species are present on or near the surface, or they are strongly bound, or not electrophile. Water formation from dihydrogen requires a redox reaction on the surface, whereas the exchange reaction does not. As in the experiments without oxidative treatment, HD is formed. The ratios of the $\mathrm{HD}$ and $\mathrm{D}_{2}$ concentrations obtained after the two different activation procedures are compared in Fig. 4 and show that the ability of silver to catalyze the H/D exchange is promoted through the intermittent $\mathrm{O}_{2}$ treatment.

\section{2. $D S C$}

Interaction of supported silver catalysts with $\mathrm{H}_{2}$ was investigated by DSC measurements. Fig. 5a shows calorimetric responses during dosing of $\mathrm{H}_{2}$ pulses into the carrier gas. Very little heat evolves during $\mathrm{H}_{2}$ pulses at $373 \mathrm{~K}$; however, at higher temperatures the heat signals become more pronounced. Although hard to discern, the positive signals are followed by negative heat signals from desorption, which are broader and are tailing more than the sharp adsorption signals. Except for the first few pulses, the adsorption signals are equally sized and the areas of the desorption signal are only slightly smaller than those of the adsorption signals. This behavior indicates that adsorption is largely reversible. The first signals are higher than the subsequent signals, indicating that some irreversible ad- 

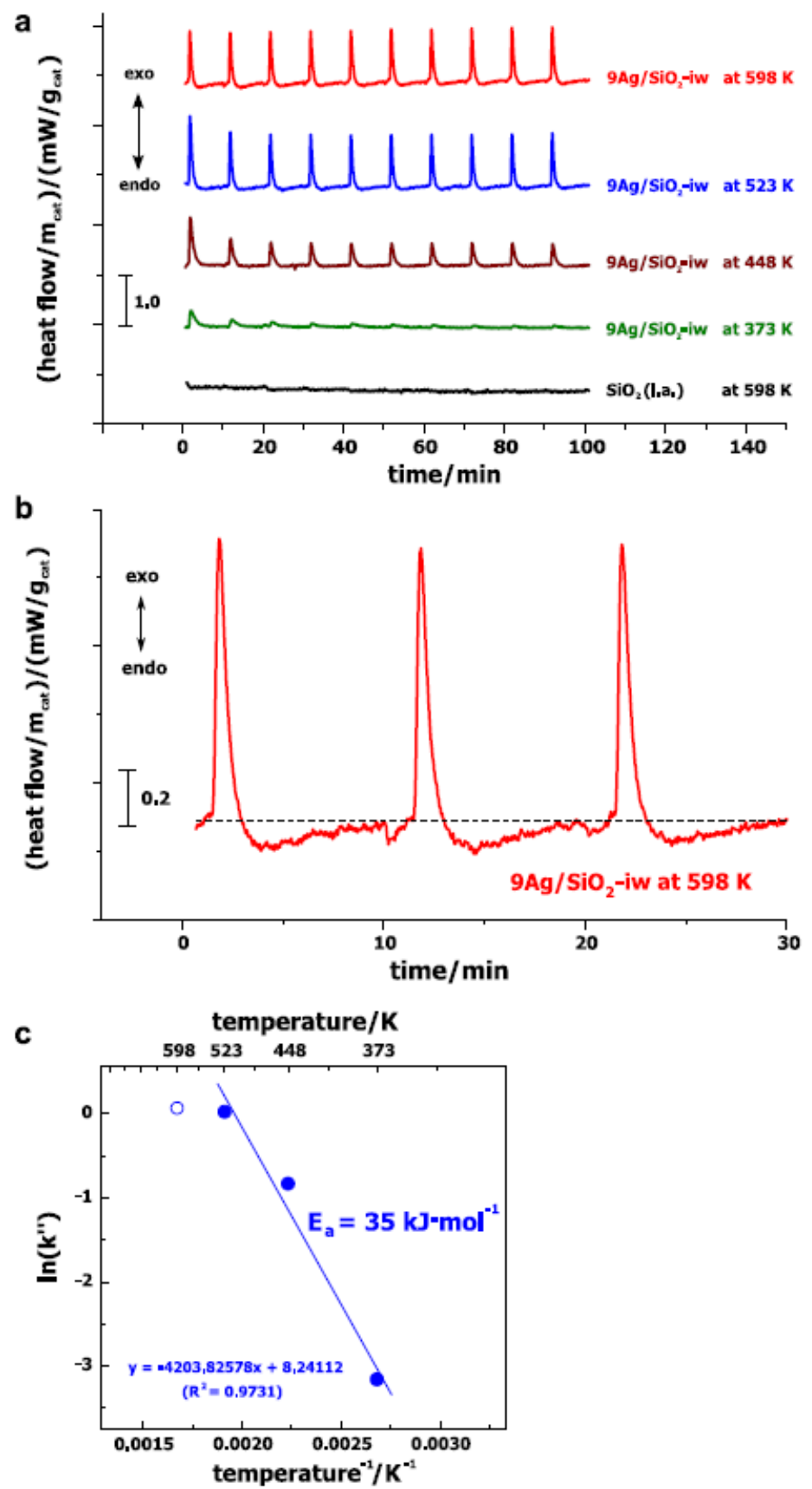

Fig. 5: (a) Heat flow during temperature dependent calorimetric experiments of hydrogen adsorption on $9 \mathrm{Ag} / \mathrm{SiO}_{2}$-iw (standard pre-treatment). Hydrogen pulses of $8 \times 10^{-8} \mathrm{~mol} \mathrm{H} /$ pulse were applied periodically (every $10 \mathrm{~min}$ ) at $373 \mathrm{~K}, 448 \mathrm{~K}, 523 \mathrm{~K}$ and $598 \mathrm{~K}$. (b) Enlarged section of (a). (c) Arrhenius plot obtained from DSC data.

sorption occurs initially, particularly at low temperature. However, only minute amounts of hydrogen remain irreversibly adsorbed on the supported silver catalyst even during the initial pulses, and it is impossible to determine hydrogen adsorption enthalpies.

The highest point in the heat evolution signals was taken as a measure of the adsorption rate. It is assumed that the maximum rate is reached before depletion of $\mathrm{H}_{2}$ in the pulse can have an effect on the rate. An Arrhenius plot can then be assembled, which is shown in Fig. 5b. The measurement at the highest temperature of $598 \mathrm{~K}$ did not fall in line with the others; most likely it is outside of the regime that is controlled by adsorption kinetics. An activation energy of about $35 \mathrm{~kJ} / \mathrm{mol}$ resulted from the analysis of the slope.

In a comparable experiment with $\mathrm{Pt} / \mathrm{SiO}_{2}$ no $\mathrm{H}_{2}$ reaches the MS at the reactor outlet, consistent with irreversible adsorption; only at higher pulse numbers than in this experiment does $\mathrm{H}_{2}$ become detectable in the effluent. Compared to conventional hydrogenation catalysts such as $\mathrm{Pt} / \mathrm{SiO}_{2}$ the interaction of hydrogen with silver catalysts is 
thus very weak. Blank measurements with $\mathrm{SiO}_{2}$ (l.a.) reveal no interaction at all, even at $598 \mathrm{~K}$.

To confirm the effect of an $\mathrm{O}_{2}$ pretreatment that was observed for unsupported silver in the TAP experiments, a similar pretreatment was carried out before the DSC measurements. $10 \mathrm{Ag} / \mathrm{SiO}_{2}$-imp was activated in two different ways: by conventional pretreatment (PT2), or by a sequence including $\mathrm{O}_{2}$ exposure before the final reduction step at $578 \mathrm{~K}$ (PT3). Average peak areas were obtained through integration of 70 pulses during a periodic pulse experiment. The heat that evolved during interaction of silver (after normal pre-treatment) with a $\mathrm{H}_{2}$ pulse was approximately $2.4 \mathrm{~mJ}$, after the pre-treatment in $\mathrm{O}_{2}$ it was about $3.6 \mathrm{~mJ}$. The higher integral heat could indicate a higher heat per adsorbed hydrogen or a higher number of adsorbed hydrogen species. The catalyst was reduced after the $\mathrm{O}_{2}$ exposure as in the conventional pretreatment, and hence additional contributions from reduction enthalpy are not expected to contribute to the result. During the pulse experiment the formation of water was not detected by MS.

\subsection{FTIR spectroscopy}

The $\mathrm{H} \rightarrow \mathrm{D}$ exchange of the support's silanol groups through reaction with $\mathrm{D}_{2}$ was monitored by infrared spectroscopy. During this process the $v(\mathrm{OH})$ band at $3740 \mathrm{~cm}^{-1}$ is diminishing, while the intensity of the $v(\mathrm{OD})$ band at $2760 \mathrm{~cm}^{-1}$ is increasing, as shown in Fig. 6a. Band areas were determined by integration as exemplified in Fig. 6 b. Development of the area of the $v(\mathrm{OD})$ band for several catalysts and two different temperatures is presented in Fig. $6 c$. Repeat measurements of the exchange were compared without further analysis and after normalization to the wafer area weight, but in both cases the obtained curves of the band area as a function of time were not congruent. However, normalization of the band area values to their saturation value shows that the shape of the curves is very well reproducible.

Exchange on silica proceeds rapidly in the beginning and then slows down. The curves obtained for the metalcontaining catalysts are characterized by an even steeper beginning than that of the silica, consistent with a very fast initial rate, and a slow approach to a final value. The presence of metals on the support influence the exchange rates, and the initial rates increase in the following order: $\mathrm{SiO}_{2}<$ $\mathrm{Ag} / \mathrm{SiO}_{2} \ll \mathrm{Pt} / \mathrm{SiO}_{2}$. As expected, increasing exchange rates are observed with increasing temperatures.

The kinetics of the exchange reaction were analyzed in two ways. First, the method of initial rates was applied. The OD band area grows linearly with time for the first few minutes and the slope during this period was taken as a measure of the rate. Assuming that variations of the $\mathrm{D}_{2}$ partial pressure and the surface concentration of $\mathrm{OH}$ groups are negligible during this short time span, the rate becomes proportional to the rate constant and an Arrhenius plot can be derived. An example is given in Fig. 6d. The results of this method were found to depend significantly on the selection of points. The obtained plots were always characterized by two slopes. The higher slope (at lower temperatemperatures) was used to derive the activation energy for the isotopic exchange reaction on $\mathrm{Ag} / \mathrm{SiO}_{2}$. The mode of the obtained distribution was about $26 \mathrm{~kJ} / \mathrm{mol}$.

Because of the uncertainty resulting from the analysis of initial rates, the whole curves were also analyzed and were found to be well described by the following function:

$$
\operatorname{area}(O D)=b \cdot \frac{(K \cdot t)^{c}}{1+(K \cdot t)^{c}}
$$

The parameter c approaches a value of 0.5 for $9 \mathrm{Ag} / \mathrm{SiO}_{2}$-iw at temperatures above $353 \mathrm{~K}$ and for $\mathrm{Pt} / \mathrm{SiO}_{2}$ at $313 \mathrm{~K}$, whereas for $\mathrm{SiO}_{2}$ a value close to one was obtained for $\mathrm{c}$ at a temperature of $393 \mathrm{~K}$. The parameter $\mathrm{b}$ represents the final value of the OD band area (after infinitely long reaction time). Table 1 shows the fit results; a maximum of $900 \mathrm{~min}$ was analyzed. The ratio of the final OD band area to the disappeared $\mathrm{OH}$ band area varied between about 0.63 and 0.73 , indicating a lower molar absorption coefficient of the $\mathrm{OD}$ relative to the $\mathrm{OH}$ vibration. The bands of the $\mathrm{OH}$ groups never disappear entirely; the highest observed conversion was $68 \%$ after reacting silica with $\mathrm{D}_{2}$ for $48 \mathrm{~h}$ at $393 \mathrm{~K}$.

Table 1: Fit results of OD band area evolution with time applying Eq. (1). Parameters obtained from fitting of the non-normalized experimental data up to $900 \mathrm{~min}$.

\begin{tabular}{lccccc}
\hline Catalyst & $\mathrm{T} / \mathrm{K}$ & $\mathrm{OD}_{\text {end }} / \mathrm{cm}^{-1}$ & $\mathrm{c}$ & $\mathrm{K} / \mathrm{min}^{-1}$ & $\mathrm{R}^{2}$ \\
\hline $6 \mathrm{Pt} / \mathrm{SiO}_{2}$-iw & 313 & 47 & 0.50 & 0.03893 & 0.99894 \\
$9 \mathrm{Ag} / \mathrm{SiO}_{2}$-iw & 393 & 49 & 0.50 & 0.01032 & 0.99932 \\
$9 \mathrm{Ag} / \mathrm{SiO}_{2}$-iw & 393 & 58 & 0.53 & 0.00863 & 0.99934 \\
$9 \mathrm{Ag} / \mathrm{SiO}_{2}$-iw & 373 & 48 & 0.50 & 0.0074 & 0.99861 \\
$9 \mathrm{Ag} / \mathrm{SiO}_{2}$-iw & 373 & 44 & 0.53 & 0.00893 & 0.99867 \\
$9 \mathrm{Ag} / \mathrm{SiO}_{2}$-iw & 353 & 61 & 0.57 & 0.00558 & 0.99886 \\
$9 \mathrm{Ag} / \mathrm{SiO}_{2}$-iw & 353 & 51 & 0.51 & 0.00792 & 0.99827 \\
$9 \mathrm{Ag} / \mathrm{SiO}_{2}$-iw & 333 & 45 & 0.57 & 0.00629 & 0.99759 \\
$9 \mathrm{Ag} / \mathrm{SiO}_{2}$-iw & 333 & 39 & 0.55 & 0.00536 & 0.99843 \\
$9 \mathrm{Ag} / \mathrm{SiO}_{2}$-iw & 313 & 39 & 0.73 & 0.00492 & 0.99892 \\
$9 \mathrm{Ag} / \mathrm{SiO}_{2}$-iw & 313 & 43 & 0.75 & 0.00474 & 0.99907 \\
$\mathrm{SiO}$ & \\
\hline
\end{tabular}

\section{Discussion}

\subsection{Activation of dihydrogen}

The TAP data provide evidence that HD is not formed in measurable amounts when a mixture of $\mathrm{H}_{2}$ and $\mathrm{D}_{2}$ is brought into contact with silica for less than a second at temperatures up to $673 \mathrm{~K}$. There are two possible routes for the formation of HD on silica, one is through activation 
a

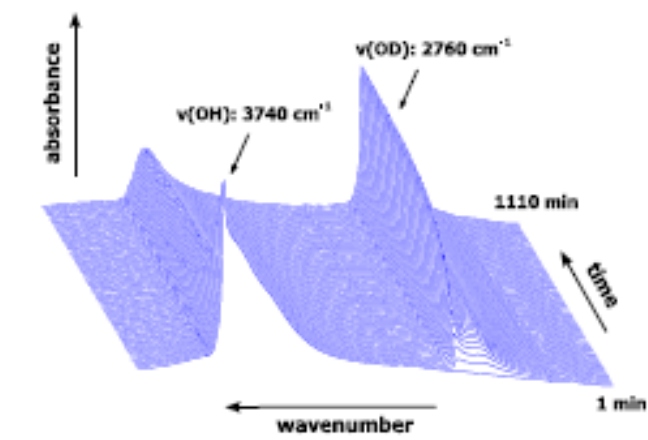

C

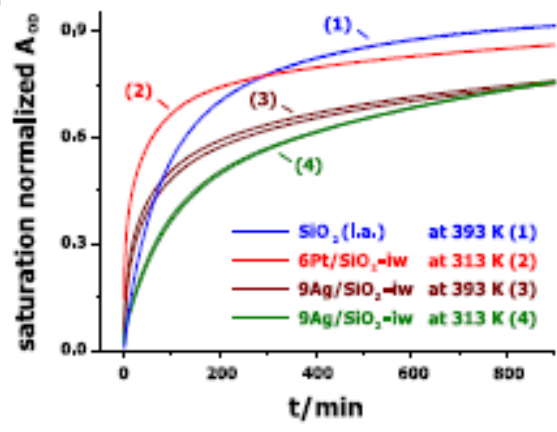

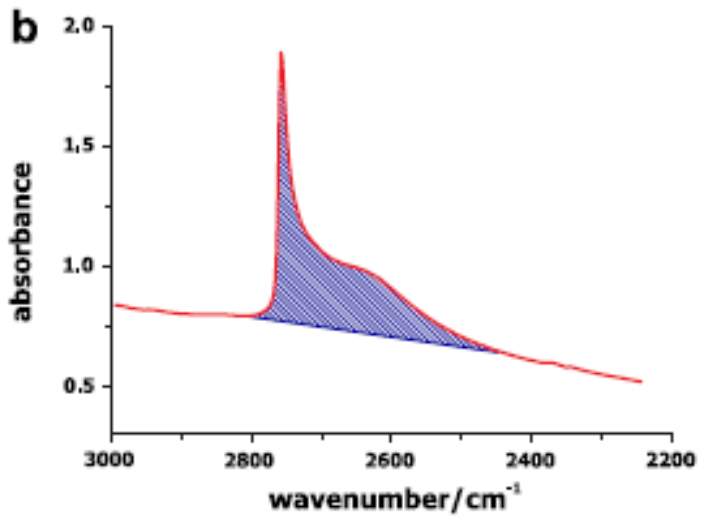

temperature/ $\mathbf{K}$

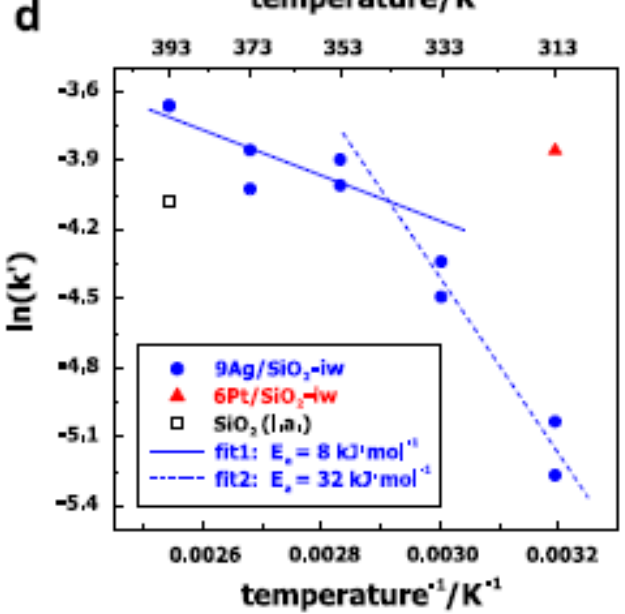

Fig. 6: a) IR spectra of silica during HD-exchange with $106 \mathrm{hPa} \mathrm{D}_{2}$ at $393 \mathrm{~K}$; b) Integration range; c) Development of the $v(\mathrm{OD})$ band at 2760 $\mathrm{cm}^{-1}$ with time for $\mathrm{SiO}_{2}, \mathrm{Ag} / \mathrm{SiO}_{2}$, and $\mathrm{Pt} / \mathrm{SiO}_{2}$ at various temperatures. $\mathrm{D}_{2}$ pressure $110 \mathrm{hPa}$ (static atmosphere). d) Arrhenius plot obtained from analysis of initial rates of $\mathrm{OD}$ band growth.

of $\mathrm{H}_{2}$ and of $\mathrm{D}_{2}$ and subsequent interaction of the activated species; the other is through an exchange reaction of $\mathrm{D}_{2}$ with surface $\mathrm{Si}-\mathrm{OH}$ groups. Neither of these two pathways proceeds with a high enough rate to yield detectable amounts of HD in the TAP experiments. This result is not necessarily in contradiction with the report of Bittner et al. [34], who did observe HD in a pulse experiment with several minute long pulses. Indeed, the IR data show that at prolonged reaction times, $\mathrm{Si}-\mathrm{OD}$ groups are formed on the surface. Theoretically, this reaction could occur without the formation of $\mathrm{HD}$, if two $\mathrm{OH}$ groups reacted with $\mathrm{D}_{2}$ to give two OD groups and $\mathrm{H}_{2}$. The gas phase was not analyzed for HD in the IR experiments.

The observed kinetics for the exchange of Si-OH to $\mathrm{Si}-\mathrm{OD}$ groups can be interpreted after reformulating Eq. 1. The ratio $\Theta$ of the area of the forming OD-band to its final value $\mathrm{b}$ corresponds to the fraction of exchanged $\mathrm{OH}$ groups to exchangeable $\mathrm{OH}$ groups. It is assumed that the fraction of non-exchangeable $\mathrm{OH}$ groups is not accessible. This fraction has been reported to vary depending on the type and treatment of silica [64]. The reacted fraction $\Theta$ is then obtained as follows:

$$
\Theta=\frac{(K t)^{c}}{1+(K t)^{c}}
$$

The exchange rate is obtained through differentiation:

$$
\frac{d \Theta}{d t}=c K^{c} \frac{t^{c-1}}{\left(1+(K t)^{c}\right)^{2}}
$$

For silica, c was close to 1 . For c=1 Eq. (3) simplifies to

$$
\frac{d \Theta}{d t}=\frac{K}{(1+K t)^{2}}
$$

Solving Eq. 2 for $\mathrm{t}$ (with $\mathrm{c}=1$ ) and substituting the result into Eq. 4, results in Eq. 5:

$$
\frac{d \Theta}{d t}=K(1-\Theta)^{2}
$$




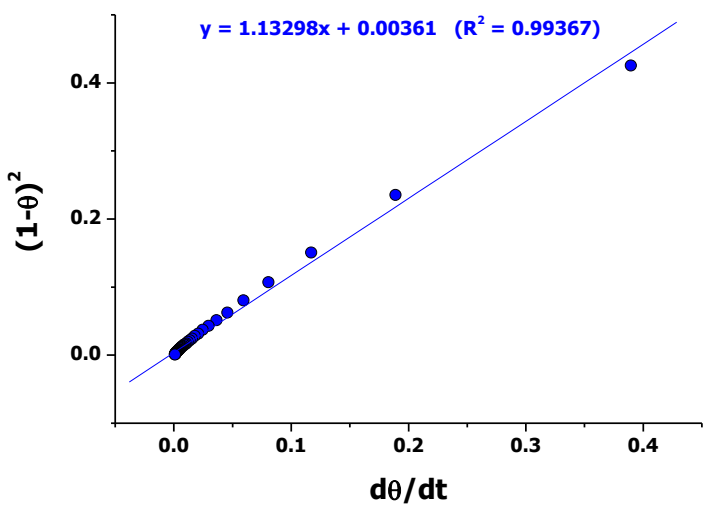

Fig. 7: Plot showing the relation between $(1-\Theta)^{2}$ and $d \Theta / d$. Data from $\mathrm{SiO}_{2}$ at $393 \mathrm{~K}$ and $105 \mathrm{hPa} \mathrm{D}_{2} \cdot(1-\Theta)^{2}$ calculated from OD band area normalized to the final value $\mathrm{b}$ as obtained by fit; derivative $\mathrm{d} \Theta / \mathrm{dt}$ calculated from fitted curve (Eq. 1) to reduce noise.

Such a rate law is consistent with dissociative Langmuir adsorption kinetics, that is, when two free sites are needed in order to adsorb two fragments of a molecule after dissociation. A plot of $\mathrm{d} \Theta / d t v s$. $(1-\Theta)^{2}$ is shown for pure silica in Fig. 7. The correlation is close but not perfect as is expected because the fit of the entire data set yielded a value of $c=0.9$. A value of $c=1$ is obtained when only the first $900 \mathrm{~min}$ (Table 1) are considered. The rate of exchange observed for pure silica thus closely approaches Langmuir kinetics for dissociative adsorption. Carter et al. [42] also observed that OH/OD exchange kinetics (on alumina) follow the laws of chemisorption kinetics. The sites for activation of the $\mathrm{D}_{2}$ could be the support $\mathrm{OH}$ groups themselves or neighboring sites. It was shown by IR spectroscopy that $\mathrm{H}_{2}$ and $\mathrm{D}_{2}$ interact directly with the Si-OH groups of silica, at least at liquid $\mathrm{N}_{2}$ temperature [14]. The interaction is rather weak as indicated by a red-shift of the $\mathrm{OH}$ frequency of only $15-18 \mathrm{~cm}^{-1}$, and this type of adsorbate may not be the precursor for the isotopic exchange reaction. In conclusion, a mechanism in which a $\mathrm{D}_{2}$ molecule directly interacts with a single $\mathrm{OH}$-group does not seem likely; rather, the observed rate law suggests that two sites are necessary for the activation of dihydrogen on a silica surface.

The TAP data indicate that activation and dissociative adsorption of $\mathrm{H}_{2}$ and $\mathrm{D}_{2}$ takes place on silver at $673 \mathrm{~K}$. The presence of a support is not required, as suspected previously $[14,16]$. Following the argument that the filled d-band of silver prevents interaction with $\mathrm{H}_{2}[32,33,65]$, one may in turn suspect that silver that interacts with dihydrogen is characterized by structural defects at the surface or impurities that alter the electronic situation. The activated species from $\mathrm{H}_{2}$ and $\mathrm{D}_{2}$ on the silver surface must have opportunity to react with each other, which may arise because they are retained on the surface long enough while having sufficient mobility, or because the coverage is significant. When $\mathrm{H}_{2}$ and $\mathrm{D}_{2}$ were sequentially pulsed over unsupported silver with various time delays (from 0 to 4 s),
HD was observed during the $\mathrm{D}_{2}$ pulse. The amount of $\mathrm{HD}$ formed decreased with increasing pulse intervals. It follows that, albeit the high temperature of $673 \mathrm{~K}$, activated hydrogen species on silver have a lifetime in the second range. This conclusion is corroborated by the DSC data, which show desorption of $\mathrm{H}_{2}$ to be much slower than adsorption over a temperature range from 373 to $523 \mathrm{~K}$.

Given the fact that activated hydrogen is retained by silver for several seconds, spillover onto the support, followed by migration and reaction has to be considered. Acrolein is known to interact with silanol groups $[66,67]$ and if active hydrogen became available, the hydrogenation reaction could also occur on the support. The rate of HD exchange of $\mathrm{OH}$ groups of the silica support in the presence of silver in comparison to the exchange of the pure support is an indicator for the availability of activated hydrogen on the entire support surface. The rate of the exchange reaction may be determined by activation of $\mathrm{D}_{2}$ on the silver surface, by spillover, or by migration; of course there is a contribution from reaction of $\mathrm{D}_{2}$ with the silica surface but this reaction is slow. The results of the fits in Table 1 show that at sufficiently high temperatures, $\mathrm{c}$ in Eq. 2 assumes a value of 0.5 . In this case, the following differential equation results for $\Theta$ :

$$
\frac{d \Theta}{d t}=1 / 2 K \frac{(1-\Theta)^{3}}{\Theta}=1 / 2 K\left(\frac{1}{\Theta}-3+3 \Theta-\Theta^{2}\right)
$$

At small values of $\Theta$, the first term in the parentheses is dominant. A rate inversely proportional to the degree of conversion (here the degree of exchange) is known from reactions limited by one-dimensional diffusion, in which one of the reactants has to diffuse through an increasing distance of already reacted material. Dissociation of $\mathrm{D}_{2}$ on platinum proceeds easily, and the TAP and DSC results indicate that $\mathrm{D}_{2}$ dissociates on silver at elevated temperatures. If one envisions rapid activation of $\mathrm{D}_{2}$ on a metal particle and migration of an activated deuterium species across the surface to un-exchanged $\mathrm{OH}$ groups, diffusion indeed may become rate-limiting. This interpretation is in line with a switch to a diffusion limited D-H exchange reaction of various oxides in supported rhodium catalysts at temperatures above $353 \mathrm{~K}$ [68]. The reaction front should progress radially from the silver center and the rate law of two-dimensional diffusion, with the rate being proportional to $-1 /(\ln (1-\Theta))$, should be applicable [69]. However, for very small values of $\Theta(<0.05)$ these two rate laws are not distinguishable because the radial spread is insignificant as long as the reaction front is close to the metal particle. For higher exchange degrees, Eq. (6) is not so easily interpretable. It is conceivable that at a high degree of exchange the role of the metal becomes insignificant and a rate law similar to that observed for pure silica should apply. Consistent with this consideration is the fact that the highest order term is $\Theta^{2}$

The following picture on the dihydrogen activation and further reaction on silica-supported silver catalysts evolves from the TAP, DSC, and IR results. The adsorption 
of dihydrogen on silver is activated, as is typical for many dissociative adsorptions, and proceeds with measurable rates only at elevated temperatures. The apparent activation energy for $\mathrm{H}_{2}$ is estimated to be about $35 \mathrm{~kJ} / \mathrm{mol}$. The DSC data indicate that most of the hydrogen is adsorbed reversibly and desorbs within minutes once the $\mathrm{H}_{2}$ partial pressure decreases after the pulse passes. The lifetime on the surface of silver is long enough to allow the activated hydrogen species to react with a $4 \mathrm{~s}$ delayed $\mathrm{D}_{2}$ pulse in the TAP experiments. Initial rate data on the exchange of $\mathrm{Si}-\mathrm{OH}$ to Si-OD groups, which were found to vary greatly depending on the analysis, gave an activation energy of about 26 $\mathrm{kJ} / \mathrm{mol}$ for the reaction of $\mathrm{D}_{2}$ with $\mathrm{Ag} / \mathrm{SiO}_{2}$. One could speculate that the highest barrier may be the dissociation of $\mathrm{D}_{2}$ on silver; and the activation energy for the dissociation of $\mathrm{D}_{2}$ on silver would be expected to be higher than that of $\mathrm{H}_{2}$ because its zero point energy is $7.6 \mathrm{~kJ} / \mathrm{mol}$ lower than that of $\mathrm{H}_{2}$ [70]. However, analysis of the OD band growth kinetics indicates that at high temperatures on $\mathrm{Ag} / \mathrm{SiO}_{2}$ or in the presence of a metal that is highly active for dihydrogen dissociation, such as platinum, the reaction becomes quickly limited by diffusion of the active hydrogen species across the surface. Perhaps this is the reason why the activation energy that was obtained from the initial rates is lower than that obtained for $\mathrm{H}_{2}$ activation. Exchange of $\mathrm{D}_{2}$ with the $\mathrm{OH}$ groups on silica also occurs in the absence of a metal. This mechanism requires two sites on the surface and is very slow at low temperatures. It may contribute to the isotopic exchange of $\mathrm{OH}$ groups on silica-supported silver catalysts on patches of surface that are remote from any metal particle.

\subsection{Effect of a pre-treatment in $\mathrm{O}_{2}$}

A pre-treatment of silver catalysts in $\mathrm{O}_{2}$ was found to affect the activation of $\mathrm{D}_{2}$ and $\mathrm{H}_{2}$ by TAP and DSC measurements. Significantly more $\mathrm{HD}$ is formed after an $\mathrm{O}_{2}$ pre-treatment and a greater amount of heat is evolving during hydrogen adsorption. Catalytic results evidence a faster hydrogenation of acrolein after a pre-treatment in $\mathrm{O}_{2}$ containing atmosphere [60]. In light of the TAP and DSC results this effect can be explained by the facilitated activation of dihydrogen on the pretreated silver surface.

Treatment of silver in $\mathrm{O}_{2}$ at elevated temperatures can lead to the formation of surface, bulk, and subsurface oxygen species [50,51], which influence the state of adjacent silver atoms. According to theoretical calculations [24$26,71]$, the dissociation of dihydrogen on clean, oxygenfree silver surfaces is an endothermic process. This is seemingly in contradiction to the observed heat evolution during the DSC experiments; however an absolutely oxygen free surface may be difficult to obtain in practice [59]. Taking the effect of adjacent oxygen atoms in silver in account, dissociation of hydrogen becomes exothermic [56]. In two recent DFT investigations Rösch and coworkers demonstrate how oxygen in different forms on the silver surface lowers the activation barrier for the dissociative adsorption of $\mathrm{H}_{2}$ and can even make it strongly exothermic through formation of very stable products [57,71]. Water and $\mathrm{OH}$ groups can be formed in the reaction of an oxygencontaining silver surface with $\mathrm{H}_{2}$ but active hydrogen species are also generated [57].

Treatment of silver in $\mathrm{O}_{2}$ does not only increase the conversion rate of the reactant (acrolein) but also affects the selectivity. In general, metals and alloys that interact weakly with $\mathrm{H}_{2}$ seem to have a higher selectivity towards the unsaturated alcohol in the hydrogenation of $\alpha, \beta$ unsaturated aldehydes. For example, supported gold catalysts interact weakly with $\mathrm{H}_{2}[72,73]$ compared to conventional hydrogenation catalysts such platinum or palladium and exhibit high selectivities towards allylic alcohols [7476]. Modification of $\mathrm{Rh} / \mathrm{SiO}_{2}$ by tin decreases the heat of $\mathrm{H}_{2}$ adsorption compared to the monometallic $\mathrm{Rh} / \mathrm{SiO}_{2}$ catalyst [77-79] whereas the intramolecular selectivity to transcrotylalcohol in the gas phase hydrogenation of crotonaldehyde strongly increases with the $\mathrm{Sn} /(\mathrm{Rh}+\mathrm{Sn})$ ratio (up to $\mathrm{x}=0.6$ ). It is thus somewhat surprising that the second effect of the pre-treatment in $\mathrm{O}_{2}$, which enhances the interaction of silver with $\mathrm{H}_{2}$, is a higher selectivity toward allyl alcohol. There are two possible explanations for this phenomenon, namely the nature of the active hydrogen species in the presence and absence of oxygen on the surface differs, with the species in the presence of oxygen favoring $\mathrm{C}=\mathrm{O}$ bond hydrogenation. Alternatively, the adsorption geometry of the second reactant, acrolein, could be affected through the pretreatment in $\mathrm{O}_{2}$. Oxygen species on the silver surface can affect the nature of the acrolein adsorbate; simple changes in the silver surface morphology such as faceting that occur through contact with $\mathrm{O}_{2}$ at elevated temperatures [51,52] can also lead to sites with an altered geometry and hence an altered acrolein adsorbate structure. Oxygen is in principle also amply available during the hydrogenation catalysis, as it is present in the reactants and products.

\section{Summary and conclusions}

1. Dissociation of $\mathrm{H}_{2}\left(\mathrm{D}_{2}\right)$ occurs on unsupported silver catalysts (TAP) as well as on the metal-free support (FTIR spectroscopy).

2. Adsorption of $\mathrm{H}_{2}$ on silver is activated (DSC).

3. Silica-supported silver catalysts exhibit a very weak interaction with hydrogen compared to similar platinum catalysts.

4. The presence of a metal leads to an increase of the $\mathrm{H} \rightarrow$ D-exchange rates of the supports silanol groups $\left(\mathrm{SiO}_{2}<\mathrm{Ag} / \mathrm{SiO}_{2} \ll \mathrm{Pt} / \mathrm{SiO}_{2}\right)$. At low temperatures, the dissociation of dihydrogen on the silver is ratedetermining, at high temperatures or on platinum, the diffusion of activated hydrogen on the support becomes rate-limiting (DSC, FTIR spectroscopy).

5. A pre-treatment with $\mathrm{O}_{2}$ leads to an increased interaction with hydrogen (DSC, TAP) and thus presumably 
a higher coverage, which leads to faster hydrogenation of acrolein (catalysis).

In light of the results, the conditions of acrolein hydrogenation on silver (523-598 K, 10-50 bar) can be understood in that a minimum temperature is required to activate hydrogen, while high hydrogen pressure is beneficial for the hydrogen coverage on silver. However, there is more than one effect of pressure. The total pressure needs to be $100 \mathrm{hPa}$ or higher to produce allylic alcohol $[14,15,80,81]$, which is caused by variations in the mode of acrolein adsorption as the surface becomes more populated (by acrolein or other adsorbates). The improvement of catalytic performance through a treatment in $\mathrm{O}_{2}$ is explained by residual oxygen in silver, which facilitates the dihydrogen activation, presumably through withdrawing electron density from the d-band states. $\mathrm{H}_{2}$ can be activated on unsupported silver, but the support affects the particle size and

\section{References}

[1] H. Sperber, Chem. Ing. Tech. 41 (1969) 962.

[2] W.M.H. Sachtler, Catal. Rev. Sci. Eng. 4 (1971) 27.

[3] P.A. Kilty, W.M.H. Sachtler, Catal. Rev. Sci. Eng. 10 (1974) 1.

[4] X.E. Verykios, F.P. Stein, R.W. Coughlin, Catal. Rev. Sci. Eng. 22 (1980) 197.

[5] W.M.H. Sachtler, C. Backx, R.A. Van Santen, Catal. Rev. Sci. Eng. 23 (1981) 127.

[6] R.A. van Santen, H.P.C.E. Kuipers, Adv. Catal. 35 (1987) 265.

[7] O.V. Krylov, V.A. Matyshak, Russ. Chem. Rev. 64 (1995) 167.

[8] J.G. Serafin, A.C. Liu, S.R. Seyedmonir, J. Mol. Catal. A: Chem. 131 (1998) 157.

[9] A. Nagy, G. Mestl, T. Rühle, G. Weinberg, R. Schlögl, J. Catal. 179 (1998) 548.

[10] A. Nagy, G. Mestl, Appl. Catal., A 188 (1999) 337.

[11] A.J. Nagy, G. Mestl, R. Schlögl, J. Catal. 188 (1999) 58.

[12] J.R. Monnier, Appl. Catal., A 221 (2001) 73.

[13] A. Knop-Gericke, E. Kleimenov, M. Hävecker, R. Blume, D. Teschner, S. Zafeiratos, R. Schlögl, V.I. Bukhtiyarov, V.V. Kaichev, I.P. Prosvirin, A.I. Nizovskii, H. Bluhm, A. Barinov, P. Dudin, M. Kiskinova, Adv. Catal. 52 (2009) 213.

[14] M. Bron, D. Teschner, A. Knop-Gericke, F.C. Jentoft, J. Kröhnert, J. Hohmeyer, C. Volckmar, B. Steinhauer, R. Schlögl, P. Claus, Phys. Chem. Chem. Phys. 9 (2007) 3559.

[15] M. Bron, D. Teschner, A. Knop-Gericke, B. Steinhauer, A. Scheybal, M. Hävecker, D. Wang, R. Födisch, D. Hönicke, A. Wootsch, R. Schlögl, P. Claus, J. Catal. 234 (2005) 37.

[16] M. Bron, E. Kondratenko, A. Trunschke, P. Claus, Z. Phys. Chem. 218 (2004) 405.

[17] M. Steffan, M. Lucas, A. Brandner, M. Wollny, N. Oldenburg, P. Claus, Chem. Eng. Technol. 30 (2007) 481.

[18] M. Steffan, M. Lucas, A. Brandner, P. Claus, M. Wollny, N. Oldenburg, Chem. Ing. Tech. 78 (2006) 923.

[19] A.F. Benton, J.C. Elgin, J. Am. Chem. Soc. 48 (1926) 3027.

[20] A.F. Benton, L.C. Drake, J. Am. Chem. Soc. 56 (1934) 255.

[21] L.C. Drake, A.F. Benton, J. Am. Chem. Soc. 56 (1934) 506.

[22] P. Avouris, D. Schmeisser, J.E. Demuth, Phys. Rev. Lett. 48 (1982) 199. the performance $[14,81,82]$. Excellent results with $\mathrm{Ag} / \mathrm{ZnO}$ $[14,81]$ suggest that the oxygen content of silver may be increased on reducible supports, which would be favorable for $\mathrm{H}_{2}$ activation.

\section{Acknowledgements}

The authors thank M. Klimczak for providing the electron microscopy images of unsupported silver. Financial support by DFG priority program 1091, grants CL168/1-5 and JE 267/3-1, is gratefully acknowledged.

[23] J.E. Demuth, D. Schmeisser, Ph. Avouris, Phys. Rev. Lett. 47 (1981) 1166.

[24] A. Eichler, G. Kresse, J. Hafner, Surf. Sci. 397 (1998) 116.

[25] A. Montoya, A. Schlunke, B.S. Haynes, J. Phys. Chem. B 110 (2006) 17145.

[26] A. Eichler, J. Hafner, A. Groß, M. Scheffler, Phys. Rev. B 59 (1999) 13297.

[27] V. Zhukov, K.D. Rendulic, A. Winkler, Vacuum 47 (1996) 5.

[28] P.R. Subramanian, J. Phase Equilib. 12 (1991) 649.

[29] F.A. Lewis, Pure \& Appl. Chem. 62 (1990) 2091.

[30] C. Kluthe, T. Al-Kassab, J. Barker, W. Pyckhout-Hintzen, R. Kirchheim, Acta Mater. 52 (2004) 2701.

[31] V. Muzykantov, H. Ehwald, A. Shestov, N. Bogdanchikova, React. Kinet. Catal. Lett. 40 (1989) 31.

[32] R.J. Mikovksy, M. Boudart, H.S. Taylor, J. Am. Chem. Soc. 76 (1954) 3814.

[33] R. Duś, E. Nowicka, Prog. Surf. Sci. 74 (2003) 39.

[34] E.W. Bittner, B.C. Bockrath, J.M. Solar, J. Catal. 149 (1994) 206.

[35] I. Yasumori, S. Ohno, Bull. Chem. Soc. Jpn. 39 (1966) 1302.

[36] S. Ohno, I. Yasumori, Bull. Chem. Soc. Jpn. 41 (1968) 2227.

[37] F.H. Van Cauwelaert, W.K. Hall, Trans. Faraday Soc. 66 (1970) 454

[38] S.W. Weller, S.G. Hindin, J. Phys. Chem. 60 (1956) 1506.

[39] V.C.F. Holm, R.W. Blue, Ind. Eng. Chem. 43 (1951) 501.

[40] V.K. Rajagopal, R.D. Guthrie, T. Fields, B.H. Davis, Catal. Today 31 (1996) 57.

[41] J.T. Kiss, I. Pálinkó, Á. Molnár, Spectrochim. Acta, Part A 52 (1996) 185.

[42] J.L. Carter, P.J. Lucchesi, P. Corned, D.J.C. Yates, J.H. Sinfelt, J. Phys. Chem. 69 (1965) 3070.

[43] J.B. Peri, R.B. Hannan, J. Phys. Chem. 64 (1960) 1526.

[44] H. Knözinger, P. Ratnasamy, Catal. Rev. Sci. Eng. 17 (1978) 31.

[45] J.B. Peri, J. Phys. Chem. 70 (1966) 2937.

[46] S.R. Seyedmonir, D.E. Strohmayer, G.L. Geoffroy, M.A. Vannice, H.W. Young, J.W. Linowski, J. Catal. 87 (1984) 424.

[47] H. Backman, J. Jensén, F. Klingstedt, J. Wärnå, T. Salmi, D.Y. Murzin, Appl. Catal., A 273 (2004) 303. 
[48] P. Claus, P.A. Crozier, P. Druska, Fresenius J. Anal. Chem. 361 (1998) 677.

[49] P. Claus, H. Hofmeister, J. Phys. Chem. B 103 (1999) 2766.

[50] C. Rehren, G. Isaac, R. Schlögl, G. Ertl, Catal. Lett. 11 (1991) 253.

[51] A.J. Nagy, G. Mestl, D. Herein, G. Weinberg, E. Kitzelmann, R. Schlögl, J. Catal. 182 (1999) 417.

[52] B. Pettinger, X. Bao, I.C. Wilcock, M. Muhler, G. Ertl, Phys. Rev. Lett. 72 (1994) 1561.

[53] G.W. Keulks, A. Ravi, J. Phys. Chem. 74 (1970) 783.

[54] Z. Qu, M. Cheng, W. Huang, X. Bao, J. Catal. 229 (2005) 446.

[55] Z. Qu, M. Cheng, X. Dong, X. Bao, Catal. Today 93-95 (2004) 247.

[56] Y. Xu, J. Greeley, M. Mavrikakis, J. Am. Chem. Soc. 127 (2005) 12823.

[57] A.B. Mohammad, I.V. Yudanov, K.H. Lim, K.M. Neyman, N. Rösch, J. Phys. Chem. C 112 (2008) 1628.

[58] S.R. Seyedmonir, D.E. Strohmayer, G.J. Guskey, G.L. Geoffroy, M.A. Vannice, J. Catal. 93 (1985) 288.

[59] F.H. Buttner, E.R. Funk, H. Udin, J. Phys. Chem. 56 (1952) 657.

[60] M. Bron, D. Teschner, U. Wild, B. Steinhauer, A. KnopGericke, C. Volckmar, A. Wootsch, R. Schlögl, P. Claus, Appl. Catal., A 341 (2008) 127.

[61] D. Walsh, L. Arcelli, Toshiyuki Ikoma, Junzo Tanaka, S. Mann, Nat. Mater. 2 (2003) 386.

[62] J. Perez-Ramirez, E.V. Kondratenko, Catal. Today 121 (2007) 160.

[63] J.T. Gleaves, G.S. Yablonskii, P. Phanawadee, Y. Schuurman, Appl. Catal., A 160 (1997) 55.

[64] V.Y. Davydov, A.V. Kiselev, L.T. Zhuravlev, Trans. Faraday Soc. 60 (1964) 2254.

[65] B.M.W. Trapnell, Proc. R. Soc. Lond. A 218 (1953) 566.
[66] G.Y. Popova, A.A. Davydov, T.V. Andrushkevich, I.I. Zakharov, Kinet. Katal. 36 (1995) 125

[67] J.E. Bailie, C.H. Rochester, G.J. Hutchings, J. Chem. Soc., Faraday Trans. 93 (1997) 4389.

[68] D. Martin, D. Duprez, J. Phys. Chem. B 101 (1997) 4428.

[69] A. Khawam, D.R. Flanagan, J. Phys. Chem. B 110 (2006) 17315.

[70] G. Herzberg, A. Monfils, J. Mol. Spectrosc. 5 (1961) 482.

[71] A.B. Mohammad, K.H. Lim, I.V. Yudanov, K.M. Neyman, N. Rösch, Phys. Chem. Chem. Phys. 9 (2007) 1247.

[72] E. Bus, J.T. Miller, J.A. van Bokhoven, J. Phys. Chem. B 109 (2005) 14581.

[73] E. Bus, J.A. van Bokhoven, Phys. Chem. Chem. Phys. 9 (2007) 2894.

[74] S. Schimpf, M. Lucas, C. Mohr, U. Rodemerck, A. Brückner, J. Radnik, H. Hofmeister, P. Claus, Catal. Today 72 (2002) 63.

[75] C. Mohr, H. Hofmeister, P. Claus, J. Catal. 213 (2003) 86.

[76] P. Claus, A. Brückner, C. Mohr, H. Hofmeister, J. Am. Chem. Soc. 122 (2000) 11430.

[77] P. Claus, Top. Catal. 5 (1998) 51.

[78] P. Claus, B. Lücke, K. Schrödter, Chem. Ing. Tech. 66 (1994) 967.

[79] P. Claus, M. Lucas, K. Schrödter, Chem. Ing. Tech. 65 (1993) 569.

[80] B. Steinhauer, PhD Thesis (in German), Technische Universität Berlin (2007).

[81] M. Bron, Habilitationsschrift (in German), Technische Universität Darmstadt (2009).

[82] W. Grünert, A. Brückner, H. Hofmeister, P. Claus, J. Phys. Chem. B 108 (2004) 5709. 